\title{
PAISAGEM: PESQUISA SOBRE O DESENHO DO ESPAÇO
}

\section{LANDSCAPE: RESEARCH ABOUT THE SPACE DESIGN}

Miranda Martinelli Magnoli

Professora titular da Faculdade de Arquitetura e Urbanismo da Universidade de São Paulo.

E-mail:mmemm@uol.com.br

لـ 


\section{RESUMO}

Este texto enfoca a disciplina Paisagismo em sua totalidade e os fundamentos os quais estruturam conceitualmente a área de Paisagismo na FAUUSP. A primeira parte é dedicada a uma visão geral das principais escolas de pensamento e a segunda se dedica a mostrar o momento de evolução, nos anos 1970, do Paisagismo na FAUUSP.

Palavras-chave: Desenho, pesquisa, paisagem, espaço livre.

\section{ABSTRACT}

This paper focuses the main concepts of landscape architecture and planning and the structuration of the landscape team at FAUUSP.

Key words: Design, research, landscape, open space. 


\title{
PAISAGEM: PESQUISA SOBRE O DESENHO DO ESPAÇO
}

\author{
LANDSCAPE: RESEARCH ABOUT THE SPACE DESIGN
}

\section{Introdução}

O Paisagismo é uma das várias disciplinas em que o espaço é abordado como objeto de trabaIho. Muitos são os impasses para essa abordagem, em face das características da evolução da cultura da paisagem, de sua correlação com o processo projetual e, mais especialmente, com as etapas analíticas desse processo. Entender o espaço como objeto de trabalho da paisagem facilita a inserção do fenômeno urbano na problemática regional; porém, desloca as especulações para as relações entre o homem e o meio ambiente. A complexidade de compreensão dessas relações, as limitações dos aspectos enfatizados, a prática de um paisagismo que não é crítico por sua herança e evolução, obscurecem intensamente a possibilidade de encontrar referenciais teóricos e metodológicos que subsidiem a prática do projeto. Essas preocupações levam à procura de estruturação de um grupo de trabalho em pesquisas. A formação do arquiteto no Brasil foi gerada e mantida com cunho eminentemente profissionalizante; por pequena que seja a contribuição que as pesquisas possam trazer julga-se que, no mínimo, tragam algum abalo na estruturação do ensino acadêmico.

Apresenta-se um breve histórico do difícil processo de estruturação desse grupo de trabalho na FAUUSP, e, a seguir, indicam-se as temáticas das pesquisas elaboradas e em andamento. Essas são elaboradas por docentes da área de Paisagismo do Departamento de Projeto, por alunos do curso de pós-graduação, por pesquisadores que contam com nossa orientação e por alunos de graduação, na condição de bolsistas de iniciação científica.

\section{A Evolução da Cultura da Paisagem e o Paisagismo como Matéria de Ensino; a Implantação na FAUUSP}

Várias são as fases em que a disciplina Paisagismo, como matéria de ensino, desenvolve-se em correlação com a evolução da cultura da paisagem. O primeiro curso universitário foi instituído nos Estados unidos, na Universidade de Harvard, junto do Lawrence Scientific School, em 1900, concedendo o título de landscape architect. $\bigcirc$ curso é decorrência da orientação e atividade de uma série de pioneiros como Thoreau, Perkins, Downing, Marsh, Law Olmsted, Charles Vaux na segunda metade do século XIX. As idéias de valorização da relação homem-natureza e de proteção dos recursos naturais, manifestadas no lluminismo por teses filosóficas, estéticas e sociais são transpostas para o planejamento do território e das cidades. É importante frisar ser o estudo global da paisagem que caracteriza o início americano da área disciplinar. A esse largo fôlego, a essa abrangência, sucede-se o interesse para os aspectos formais perceptivos, mais ligados à arquitetura e à forma urbana. Somente a partir de 1970, após uma década de 
intensas polêmicas, a área disciplinar volta, nos EUA, a assumir a globalidade, a amplitude, que caracterizou os primórdios de seu aparecimento. No início do século a implantação de uma área de ensino do Paisagismo, nas Américas, acontece somente nos EUA, e lá evoluiu em diversas fases, mas de conteúdo que se poderia dizer unitário e difuso para o país.

Nos vários países da Europa, em vista de suas diferentes situações históricas, políticas e culturais, a evolução do ensino do Paisagismo é de grande variedade de abordagens. Grosso modo, poderíamos dizer que são três as linhas principais de evolução: uma, que parte da horticultura e a esta acresce um aprofundamento de conhecimentos históricos, urbanísticos e de design: outra que, tendo como núcleo embrionário cultural valores espaciais e conhecimentos tecnológicos, procura integrar estudos teóricos e experiências dos aspectos naturais da paisagem; a terceira é própria das peculiaridades da Inglaterra, suas transformações intensas enquanto império, território e nação, perceptíveis na evolução da cultura da paisagem.

Na primeira abordagem podem ser situados os países escandinavos e os Países-Baixos, tendo a Holanda como o mais representativo na institucionalização e destinação de recursos junto de escolas e faculdades agrárias. A segunda abordagem pode ser claramente identificada pela institucionalização nas escolas politécnicas; às técnicas gráficas, à topografia, às ciências matemáticas e aos problemas de engenharia de implantação e execução de áreas viria a acrescer-se um ano de prática de campo; esta forma se desenvolveu especialmente na Alemanha. A terceira abordagem, específica da Grã-Bretanha, é evolução pela institucionalização anterior, de final do século passado; nesse período, vários cursos isolados, sem preocupação de títulos específicos, propiciando o conhecimento do paisagismo a pessoas de formação diversa. Posteriormente, desenvolveu especializações para pessoas de formação com disciplinas afins, como arquitetos, naturalistas ligados aos aspectos das comunidades vegetais, às ciências do solo, do clima, etc. Nessas duas últimas décadas a arquitetura paisagística evoluiu para o planejamento paisagístico concebido como parte integrante do planejamento territorial. É recente o nível de curso universitário autônomo e o escopo do ensino específico e diversificado para diferentes formações. A formação básica e predominante é multidisciplinar; apóia-se em um corpo docente que se qualifica para atender a três setores fundamentais:

- A formação da paisagem trata das bases naturais da mesma, para a compreensão dos aspectos em que o homem tem influência ou controle reduzido;

- a intervenção antrópica e o uso da paisagem pelo homem, cada vez com maior peso, já que as passam rapidamente do conhecimento teórico ao uso direto na totalidade do planeta;

- o desenho da paisagem; a qualidade das decisões humanas e dos desenhos da paisagem; a qualidade das decisões humanas e dos desenhos correspondentes é o conteúdo fundamental que confere o caráter às paisagens, à medida que se intensifique a intervenção consciente, compreendida em sua totalidade de relações.

No Brasil, a implantação do ensino do Paisagismo se deu pioneiramente na Faculdade de Arquitetura e Urbanismo da Universidade de São Paulo, em 1952, com a disciplina Arquitetura Paisagística. Nessa ocasião a arquitetura moderna brasileira já havia adquirido notoriedade internacional. É pioneira a introdução dessa área de estudos nos cursos de arquitetura da época no Brasil. Roberto Burle Marx, personalidade marcante, residente no Rio de Janeiro, iá participara dos projetos paisagísticos dos edifícios considerados significativos pela nova arquitetura brasileira no Rio de Janeiro, Recife e Belo Horizonte, e já havia exposto trabalhos de pintura e desenho em Nova York, Londres, São Paulo e Rio.

A época facilitava o aparecimento de experiências individuais em mercado de trabalho que, apesar de disputado pelos engenheiros, era razoavelmente generoso para parte do pequeno número de profissionais. No plano do Rio de Janeiro são previstas áreas livres, recorrendo-se a aterros ao longo do mar, adotando-se amplos traçados nesse avanço da terra; seria pro- 
jetado o conjunto residencial de Pedregulho do rio, com notável equilíbrio de relações entre os edifícios, os serviços e os espaços externos. Nessa década, instalavam-se em São Paulo arquitetos estrangeiros de grande valor.

A "cadeira" de Paisagismo seria de responsabilidade do jovem paisagista Roberto C. Cardozo, americano de origem portuguesa e recém-chegado ao Brasil. Havia estagiado com Garret Eckbo e trazia como bagagem as inovações do jardim doméstico que se alastravam, principalmente a partir da década de 1940, na Califórnia, com os trabalhos de Thomas Church, logo acompanhado por Ekcbo, Royston, Williams, Halprin e outros arquitetos paisagistas atuando na costa oeste dos EUA a partir de São Francisco.

Essa transposição, muito discutível até para nosso jardim doméstico, foi razoavelmente aceita pela "arquitetura dos arquitetos", na medida em que não pretendesse ser mais do que uma boa moldura visual da obra arquitetônica.

Foi muito intensa a influência em alguns poucos discípulos que se formaram; e suas oportunidades na arquitetura não passaram de "adorno" à obra, em seus recuos. Essa situação de vedete, transposta do autor para o edifício, não impediu que fossem elaborados vários bons projetos, quer de Roberto Coelho Cardozo quer de seus discípulos. Apesar de tudo, a própria obra arquitetônica ficaria melhor complementada, sem qualquer chance de discutir o partido inicial. Na década de 1960 as soluções do jardim de algumas moradias unifamiliares seriam objeto de rearranjo para moradias plurifamiliares; e para alguns clubes, alguns edifícios institucionais. Fundamentalmente fazendo uso da vegetação como material de execução, exigiam uma organização de implantação e de crescimento, mudanças e manutenção estranha à edificação e, pode-se dizer, inexistente.

A arquitetura dos arquitetos se alterava; os projetos dos jardins adquiriam elaboração completa; a arquitetura da cidade, porém, permanecia em um quadro obsoleto que se expandia e adensava-se em estruturas de organização física de serviços diferentes ou inexistentes e total descaso pelos espaços coletivos da população.

O primeiro concurso público para praças seria promovido em 1958, em Porto Alegre, para a praça principal de Cachoeira do Sul, no Rio Grande do Sul. Apesar de bem recebido pelo júri, pela entidade patrocinadora, a Secretaria de Viação e Obras Públicas do Estado, pelos arquitetos gaúchos, vencido pela arquiteta Miranda Martinelli Magnoli, paulista então residente em Porto Alegre, nunca seria implantado. Seria todo cuidadosamente detalhado, nunca seria pago ou executado. $O$ próximo concurso público para espaço coletivo urbano seria somente na década de 1980, com o Vale do Anhangabaú, em São Paulo.

Em 1957 e 1958, o grupo Economia e Humanismo elaboraria a "Pesquisa Lebret" para o município de São Paulo; entre as décadas de 1950 a 1970 se sucederiam vários congressos da União Internacional de Arquitetos, a carta de La Tourette, dos Andes, o Seminário da CNU em Nova Delhi sobre habitação e planejamento urbano e rural, a promulgação da lei orgânica dos municípios, a qual levaria à elaboração de inúmeros planos diretores municipais

Em São Paulo, a prefeitura levantava o cadastro das "áreas verdes" públicas municipais em 1967, elaborava projetos para mais de 20 praças, algumas, em parte, pessimamente executadas (Rosa Grena Kliass e Miranda Martinelli Magnoli); contratava estudos para organização de viveiros municipais (Rosa Grena Kliass, Miranda Martinelli Magnoli e Harri Blossfeld), executava a praça Roosevelt (Roberto Coelho Cardozo, Antônio Augusto Antunes e Marcos Souza Dias) e alojava-se nos edifícios previstos como áreas de cultura, pública e aberta, no Parque do Ibirapuera. Vários já tinham sido os espaços livres públicos previstos como praça pela legislação de loteamento que, apesar de residuais e fragmentados, seriam ocupados em novos lotes de moradias, comércio, viadutos, postos de saúde e escolas. 
Em 1968, a prefeitura municipal elaborava o Plano Urbanístico Básico e, na virada entre as duas décadas, organizava-se o Grupo Executivo da Grande São Paulo, que viria a elaborar, em 1971, o Plano Metropolitano do Desenvolvimento Integrado.

\section{As Transformações Intensas das Últimas Décadas nas Questões Comuns aos Arquitetos da América Latina e as Questões de Paisagem}

Algumas questões complexas, diretamente ligadas a nosso trabalho e nossa atuação enquanto arquitetos, parecem comuns aos vários países da América Latina; enumeramos algumas que têm se rebatido no ensino e pesquisa:

1. As especificidades das condições das populações do continente. Caberá estarmos lúcidos e críticos quanto aos modelos elaborados pelos ricos para os países pobres, aos argumentos baseados no reducionismo biológico, nos modelos de consumo, de interesse que não nos dizem respeito, aos argumentos baseados nos limites de crescimento, aos argumentos os quais mantêm "o aglutinado amorfo de seres humanos sem rosto e sem vontade".

2. As especificidades das condições ambientais e daí dos processos de desenho do ambiente por escala de atuação e por métodos próprios. Como lidar com a geração de hábitats, em cada tempo e espaço, relacionada a modelos de utilização de recursos (naturais e sociais) e a modelos de utilização do espaço estreitamente inter-relacionados? Não poderão deixar de serem analisados:

Os conflitos na ocupação territorial diretamente relacionados:

- À simultaneidade de falta de exploração de recursos em vastas zonas e fenômenos localizados de intensidade de uso de recursos em outras;

- à falta de apoio tecnológico e financeiro para encontrar respostas aos problemas ambientais que atendem às prioridades econômico-sociais;

- $\bigcirc$ grau de controle efetivo e autônomo das comunidades sobre a condução de seus processos de utilização de recursos em face da realidade social.

3. A deterioração socioeconômica que envolve o hábitat rural e a trama de articulações nos vários níveis e escalas do meio rural na estrutura do território.

4. A complexidade das políticas de urbanização, iá que os problemas são especificamente diferentes nos países subdesenvolvidos em relação aos países que são parte de nosso legado teórico. Não se pode abrir mão de uma atitude imbuída de muita consciência e clareza em relação às formas pelas quais se produz o processo acelerado de urbanização; em relação à expansão da terra urbana, a repercutir diretamente sobre os custos dos serviços, da infra-estrutura e da deterioração do ambiente; em relação aos poucos recursos financeiros os quais, em qualquer situação próxima, poderão ser destinados ao urbano.

5. A altíssima demanda de habitações com todas as interconexões de atividade e serviços vinculados à função habitação. Não se poderá abrir mão de enfrentar o desafio da localização relativa das áreas habitacionais e os condicionantes do suporte ecológico.

6. A identidade do espaço urbano comunitário com as formas de convivência cotidiana do cidadão.

As transformações amplas e profundas, em âmbito mundial, ocorridas na segunda metade do século XX, sobre a forma de utilização dos recursos do planeta, foram de tal ordem, que se constituem em um referencial histórico em relação aos séculos anteriores de intervenção antrópica. 
No Brasil, as transformações na ocupação territorial e as migrações para as áreas urbanas periodizam essas décadas enfatizando, de forma crucial nos últimos 20 anos, a problemática do meio ambiente. Nesse período as controvérsias mundiais sobre a internacionalização de utilização dos recursos naturais fizeram emergir intensamente as relações entre o desenvolvimento e as questões ambientais, a bipolarização entre países desenvolvidos e subdesenvolvidos levanta e relaciona campos de conhecimento, áreas de atuação, formas de abordagem, óticas de enfoque desenvolvidas em caminhos próprios, sem maior peso para uso imediato de suas especulações. Mais do que isso, as inter-relações, as interfaces dessas especulações passam a ser objeto de indagações e formulação de hipóteses.

Para o arquiteto brasileiro, o aspecto da organização espacial é básico, nos vários níveis e escalas do processo. A conjugação entre a dinâmica dos processos, a rapidez e o grau de transformações, a inexistência de experiências passadas similares, a necessidade de uma visão prospectiva (por mais baixo que possa ser o grau de previsão de alternativas) carregam em seu bojo questões complexas de apoio conceitual, de diretrizes metodológicas, da condução de procedimentos, de produção de preposições, de acompanhamento do processo de implantação e de avaliação dos resultados parciais e em contínua transformação. Por outro lado, o processo está acontecendo, na prática, quer ou não precedido e/ou acompanhado de especulações teóricas, de institucionalização, de clareza, por parte dos agentes essenciais das transformações.

Concomitantemente à ocupação e exploração do território pela criação e expansão de assentamentos humanos, avolumam-se dúvidas, incertezas, questionamentos quanto à validade de tais processos; estas se agudizam perante modelos de ocupação que, invocando uma produção de fins sociais, configuram-se muito mais como somente exploratórias e depredadoras; desse modo, intensificam-se as citadas incertezas diante da progressão rápida da expansão da ocupação da superfície do território nacional, vinculada aos interesses dos países estrangeiros, já há muito reconhecidos em relação a uma área sem similar em âmbito mundial.

Por outro lado, a rápida e crescente urbanização e as peculiaridades do processo brasileiro dos últimos 20 anos indicam a continuidade de concentração nos aglomerados metropolitanos e em algumas cidades principais, aumentando intensamente a necessidade de medidas que permitam algum controle sobre a amplitude de deterioração ambiental.

Maior é o questionamento, mais intensa e aguda se torna a necessidade de atuação quando é alarmantemente visível a penúria das condições de vida das populações. E, é claro, a saúde do ambiente é condição, requisito essencial para as populações; os problemas de ociosidade ou de mau uso são, de fato, ônus, em toda sua grandeza, para os pobres. É uma falácia, veiculada manipulando-se interpretações, a idéia de a questão ambiental ser um problema dos ricos: a realidade é exatamente o oposto.

Especialmente em nível acadêmico, de enfoque ecológico ao desenho das paisagens que constituem, no espaço, o meio ambiente humano, o caráter integrador desse enfoque, e as contribuições orientadoras as quais a ecologia pode trazer são fundamentais na implicação entre os processos da natureza e os processos sociais, de cuja integração decorre o meio ambiente humano. É também indispensável ao arquiteto muita clareza para com as contribuições especializadas com que se possa contar: quanto à aptidão para utilização dos ecossistemas, quanto à orientação para uso de tecnologia adequada a cada ecossistema, quanto à compatibilização entre graus de utilização com oportunidades e limitações (atuais e potenciais). A ótica pela qual os ecossistemas passam a ser focalizados, enquanto propiciadores de recursos (atuais ou potenciais/curto, médio, longo prazo) reformula as posições quanto ao homem e suas intervenções. $\bigcirc$ eixo das discussões quanto às alterações dos ecossistemas se desloca da posição de "não-alteração" para o estudo das possibilidades do conhecimento e acompanha- 
mento do processo dinâmico de alterações programadas, coordenadas, para usos humanos mais eficientes, agora e no futuro. Ao especular sobre métodos que nos permitam quadro preliminar de padrões, modelos de alternativas de utilização de espaços se abrem uma perspectiva de dar corpo à inter-relação entre os processos ecológicos e os processos sociais. $\bigcirc$ "corpo" dessa inter-relação é, para o arquiteto, a expressão do meio ambiente humano no desenho do hábitat, das paisagens.

Serão essas colocações, mesmo embrionárias, válidas? Apoiadas corretamente em teorias próprias para tais objetos? Qual o nível e grau de contribuição que várias áreas do conhecimento podem subsidiar? Quais os métodos que podemos perceber como encaminhamentos essenciais? Quais os procedimentos cuja viabilidade parece pelo menos promissora? E, a par de indagações, cujo rol se pode facilmente alongar, fica patente ser cada vez maior o volume de pessoas que, das mais variadas formações, inquieta-se à procura de novas formas de especulação, novas explicações, e, em nosso caso, muito especialmente, novas formas de ensino e pesquisa.

A institucionalização da questão ambiental como problemática do país, especificamente na última década, com a criação da Secretaria Especial do Meio Ambiente, veio intensificar, para a formação de recursos humanos, a ordenação de um arcabouço teórico (apoiado e a apoiar a prática das proposições) que possa subsidiar as novas formas de ensino.

\section{A Profissão e o Ensino do Paisagismo; a Pesquisa como Fundamento do Ensino}

A arquitetura é um dos campos de pensamento humano que teve transformações radicais na paisagem do século XIX ao século XX. $\bigcirc$ movimento da arquitetura moderna reflete seu início com uma definição nova; nesta, transformam-se as relações e os limites, os territórios e a natureza da arquitetura perante outros campos do pensamento humano. Por essa definição, enunciada em 10 de março de 1881, por William Morris de London Institution,"o meu conceito de arquitetura está na união e colaboração das artes, de modo que cada coisa esteja subordinada às outras e com essas em plena harmonia, e quando use essa palavra, esse será o significado; não um mais restrito. É uma concepção ampla, porque abraça o inteiro ambiente da vida humana: não podemos nos subtrair da arquitetura enquanto somos parte da civilização, pois que representa o conjunto das modificações sobe a superfície terrestre, em vista das necessidades humanas. Nem podemos confiar nossos interesses a uma elite de homens preparados, pedindo a eles que investiguem, descubram e criem o ambiente destinado a nos hospedar, para depois nos admirarmos perante a obra pronta, e aprendendo-a como uma coisa acabada. Isto cabe a nós mesmos. A cada um de nós cabe empenhar-se no controle e na proteção da orientação justa da paisagem terrestre, cada um com seu espírito e suas mãos, na parte que the cabe, para evitar que deixemos a nossos filhos um tesouro menor que aquele que foi deixado por nossos pais".

O caráter dessa definição só pode ser profundamente avaliado na compreensão da condição histórica da evolução cultural e nas transformações produzidas nas atividades humanas pelos impactos do progresso técnico-científico e pelos desafios ideológicos de novas organizações políticas da ordem social. É importante ressaltar que sempre o homem fez transformações sobre a superfície terrestre e essas, em seu conjunto, são obra da comunidade humana, muito mais do que isolada de algumas pessoas: é importante ressaltar o contraste com uma definição ideológica da arquitetura que distingue, seleciona entre todos os produtos humanos alguns produtos especiais, privilegiados na consideração, criados por pessoas especiais, usados por pessoas especiais e discutidos e julgados em um âmbito específico e especial.

O papel do arquiteto na história sofreu transformações; em nossa época as infindáveis discussões sobre o "perfil" do arquiteto, sobre a responsabilidade do arquiteto não indica somente 
a complexidade do mundo contemporâneo, porém, também uma certa falta de integração com a sociedade, uma certa dificuldade em naturalmente ver a profissão como útil e necessária. No Brasil, o arquiteto organizou fundamentalmente sua atuação, até aproximadamente 15 anos atrás, por meio do exercício privado em seu escritório particular. Como a obra, de elementos isolados de impacto em relação à paisagem circundante, a atuação se faz pelos mesmos parâmetros; essa simplicidade restringe, com as novas gerações, a condição de cada vez mais acirrada competição para oferecer seu produto a um mercado reduzido pela própria organização político-econômica. Seu sucesso dependia muito freqüentemente do grau de novidade, de originalidade, de destaque que poderia inserir no produto e até a divulgação deste. É secundária a qualificação de originalidade, já que salta à vista serem esses produtos, evidentemente de alguma forma "especiais", alheios ao homem comum; seriam destinados a alguém cuja característica mínima indispensável seria, pelo menos, ser "especial" nas possibilidades financeiras de realizar esse produto. Essa atuação deixa de exigir um alto nível de qualidade com soluções de habitações particulares ou em edifícios de grandes empresas ou entidades. O nível internacional e o prestígio da arquitetura moderna concebida e realizada nessas condições não impediu que o arquiteto ficasse marginalizado da maior parte dos reais problemas do hábitat. As contradições políticas, a inexistência de um processo de investigação em relação aos vários componentes do problema, a incipiente industrialização, a descontinuidade de inversões de recursos, a persistência de métodos atrasados ao invés de métodos modernos, próprios às condições específicas e econômicas, foram alguns dos fatores os quais participaram da marginalização do arquiteto. Estejamos muito claros e lúcidos que o problema do hábitat é essencial e predominantemente uma questão política, o cerne não constitui um problema técnico e a técnica não é neutra. Porém, faz-se necessário observar que a profissão, se questionada em sua evolução, se incorporada aos problemas da maioria da população, levanta uma das fortes contradições do exercício profissional. A evolução do ensino de Paisagismo da Faculdade de Arquitetura e Urbanismo da USP processa-se de 1952 a 1972 de uma forma estática, centrada nos aspectos do espaço residual das edificações ou da malha viária; a prática técnica com seu mercado de trabalho era o elemento fundamental que alimentava o ensino das faculdades. Apesar das transformações pelas quais passava a universidade, as cidades, o país, a organização mundial, os conflitos dessa prática não abalaram estruturalmente o edifício de ensino. O próprio laboratório básico, a cidade de São Paulo, transformava-se intensamente nesse período, estabelecia sua função metropolitana e articulava-se para a reorganização especial no âmbito do país, materializada, territorial, urbanística e arquitetonicamente pela implantação de Brasília.

Reprodução ampliada do que se fizera nos primeiros anos de ensino era o que se podia notar no ensino do Paisagismo, apesar desses 20 específicos anos de enormes e profundas transformações. Mudança incidental ocorreu em 1973 com alterações institucionais na área de Paisagismo devido ao esvaziamento docente decorrente nos últimos anos: já tinha deixado de existir em face das crises diversas. Apontava-se a crise das faculdades de arquitetura como localizada no ensino; as extensas transformações sociais, políticas e econômicas mundiais; as violentas mudanças institucionais no país eludiam a crise da inserção da arquitetura para novas propostas; o ensino, por outro lado, já se destinava a um número de alunos quintuplicado em relação à época da criação da faculdade. Em particular, a área do Paisagismo havia conseguido perder seus poucos docentes enquanto as demais áreas haviam triplicado (pelo menos) seus professores.

crescimento quantitativo de alunos facilitará as colocações pessimistas elitistas as quais justificariam a queda de nível de ensino: sem dúvida o crescimento poria à mostra as já existentes deficiências do sistema universitário. A melhoria de qualidade deveria ser obtida concomitantemente com o crescimento qualitativo. 
Os procedimentos didáticos dos primeiros 20 anos de FAU deveriam ser revistos, não era simplesmente o número de estudantes que exigia revisão, era também a constatação que não era aqueles conteúdos e métodos que nos serviam. Sempre se falara nos processos, na formação de consciência crítica como objeto e meta em geral; era, porém, bastante questionável em que medida essa perspectiva vinha sendo realmente atingida ou em que medida os conteúdos e métodos em voga tinham possibilidades ou mesmo diretrizes para atingi-las. Dificuldades inúmeras poderiam justificar a não-consecução desses objetivos; também dificuldades inúmeras poderiam ser criadas para somente aparentar a busca dessas metas, na prática, contribuir fortemente para a perpetuação de formas de ensino já superadas, facilitando falsas perspectivas.

A análise, em 1974, do que deveriam ser os conteúdos de ensino, levou-nos a uma revisão dos fundamentos nos quais se baseava a disciplina até então. E, a procura de um novo enquadramento teórico se colocou como essencial: as mudanças fundamentais nas diretrizes mundiais após a Segunda Guerra Mundial, os rearranjos nas relações entre os povos, o progresso do conhecimento científico, as possibilidades tecnológicas, transformavam as bases materiais da vida em escala e tempo antes inconcebível. Essas mudanças agiam de forma complexa, em todos os níveis, em articulações e combinações que levavam questões consideradas periféricas a uma posição central: novos territórios seriam ocupados para utilização de recursos ou para garantia de poder futuro sobre os recursos, novas tecnologias de comunicação contribuíram fortemente para alterar, mais do que as distâncias entre os espaços, os tempos entre as idéias e os espaços. Os padrões de comportamento se alteravam; as noções de grupo e de comunidade estimulavam o deslocamento da preocupação com o indivíduo para os problemas com a natureza: a harmonização dessas relações teria como requisito o desafio da relação do homem com o homem, a aceitação dos conflitos inerentes a essa relação de grupos, comunidades, sociedades; o respeito ao homem sem coisificá-lo, sem reduzi-lo a uma categoria da economia. Esta deveria ser meio, ao invés de finalidade. Os objetivos de desenvolvimento seriam questionados.

Essa era a paisagem do homem que sentíamos. Essa paisagem nos encontrava totalmente a descoberto, exigindo estudos, reflexões, co-participação de aptidões, contribuições multi e interdisciplinares muitas e urgentes. Organizar programas de ensino exigia investigações, profundas reflexões para apoio consistente a novas posturas na seleção e encaminhamento de problemáticas significantes: a reformulação didática que considerávamos indispensável se fazia sob questões totalmente virgens de estudos. A pesquisa passaria a ser adotada como atitude metodológica para o ensino.

A incorporação das atividades de pesquisa foi por nós vista como um dos passos para diminuir a simplificação, a redução que o arquiteto admitira em seu campo de atuação. A especialização como profissional de planos e projetos (como é dito, "de prancheta") sem um vínculo que solicite intensamente uma proposta de esforço reflexivo, especulativo, o qual o leve a conviver com outras situações de análise, diminuiu suas possibilidades de diversificação; a falta de complexidade reduz a sensibilidade para percepção das mudanças e dos valores para alternativas: esse reducionismo leva facilmente ao profissional executor sem questões, sem perguntas, sem inquietação quanto às finalidades de seu próprio trabalho e quanto a seu próprio destino.

Já em 1975 a área havia transferido seu lecionamento para o 1a ano e procurava, concomitantemente, oferecer disciplinas optativas para facilitar opção de aprofundamento ao estudante e não para especializar.

Os docentes para ingresso e seleção deveriam aceitar um regime de trabalho por menor que fosse sua própria pesquisa. Os salários da universidade serviriam de argumento para que fôssemos obrigados a observar, com desapontamento, que, ainda nessa época, alguns dos profissionais de mais experiência preferiam abrir mão de sua participação na universidade, 
na medida da condição do vínculo com a investigação: não poderiam dispor além das horas de aula: de nossa parte já sabíamos o que se poderia esperar do professor "de passagem" o qual somente pode, rápida e salutariamente, dispor de algumas horas para comunicar o produto de sua obra; como se questionar também qual é o cliente, qual é o contribuinte, qual é o papel de uma universidade pública?

Em final de 1976 foram admitidos os cinco novos docentes, praticamente entre aqueles que podiam aceitar as condições mínimas colocadas. Os poucos nomes privilegiados no mercado de trabalho aceitaram, no máximo, o regime de turno parcial e desde que pudessem ter horários variáveis em função do andamento de seus escritórios.

A partir de 1976 procuravam-se aperfeiçoar, institucionalmente, os mecanismos de participação nos programas da faculdade. Seriam revalorizadas as organizações de grupos, procurar-se-ia articular os grupos, os níveis de programações didáticas da graduação e da pós-graduação. Os grupos procurariam engajar-se na obtenção de recursos, de lugar, de pessoal, de infra-estrutura e financeiros. Os grupos estudariam as problemáticas fundamentais e prioritárias a desenvolver e dariam a cada um o seu "espaço" e recursos, mesmo extremamente limitados.

Em 1977 os novos docentes iniciavam sua participação nos cursos de pós-graduação na condição de discentes e com um projeto de pesquisa a desenvolver.

Em 1978 seria implantado o PROGRAMA DE PESQUISA - FAU; pretendia valorizar, em âmbito institucional, as investigações, reorganizar as atividades isoladas, em grupos de totalidade, mantendo as individualidades e estimulando as interações, estimular o caminho para reformulação dos programas didáticos, a partir das prioridades de investigação definidas pelos grupos, enlaçar a pós-graduação com a graduação pelo engajamento de docentes e discentes em ambos os níveis e propiciar a participação, ainda limitada por escassez de recursos financeiros, de alunos do curso de graduação nos projetos de pesquisa individuais.

Intensa falta de professores, de infra-estrutura mínima e de recursos são, na área de Paisagismo, problemas dramáticos. A falta de professores é problema específico da área na faculdade e decorrente de atuação na "cadeira" no período de 1952 a 1972. Aos professores atuais, em número de seis, destinados para área de 1972 a 1976, não mais possível acrescer qualquer docente, por uso e abuso da crônica alegada - falta de recursos. Quer para o docente-pesquisador quer para o desenvolvimento das pesquisas, os recursos são pouquíssimos ou inexistentes, devem sempre ser obtidos em entidades sem a mais íntima colaboração de instituição; a operacionalização interna é altamente prejudicada. As escolas não assumiram, de fato, a pesquisa como elemento estruturador. Os debates ainda são raros e incipientes. $\bigcirc$ significado e o papel da pesquisa ainda é de pouco interesse. $\bigcirc$ método se confunde com técnicas, procedimentos, etapas, desnudando a fragilidade do processo de elaboração e reduzindo, freqüentemente, a atitude especulativa e a aleatória coleta de dados. Apesar das dificuldades e do clima geral pouco propício, foi possível obter, no decorrer dos últimos anos, a configuração da validade em prosseguir na atitude. $\bigcirc$ desenvolvimento das pesquisas viria a propiciar a reorganização de conteúdos curriculares, pelo menos alguma identificação mais clara de objetivos nas atividades docentes e reavaliação de procedimentos didáticos: é, sem dúvida, meio de transformação das estruturas de ensino e produção do conhecimento.

O programa de pesquisa procura coordenar a interação das pesquisas propostas pelos departamentos. Áreas de pesquisa se formaram, constituíram-se institucionalmente; os campos de pesquisa considerados prioritários em cada área são definidos por linhas de pesquisa e os trabalhos individuais e de grupo com objetivos próximos são agrupados em núcleos. A área de pesquisa Paisagismo tem suas linhas esquematizadas pelos enfoques preponderantes de análise de suas temáticas, procurando sempre a interação entre as várias escalas do território ao lugar. 


\section{Pesquisa da Área}

As pesquisas são agrupadas pelos aspectos seguintes: conceituais e de método; da paisagem do "lugar" - cotidiano da cidade, cotidiano da habitação; dos materiais-suporte da organização físico especial da paisagem.

No primeiro aspecto as pesquisas são:

- Paisagismo e teoria, professora Miranda Martinelli Magnoli.

- Paisagem e metodologia: uma revisão conceitual, professora Maria Angela Faggin Pereira Leite - Orient. professora Miranda M. Magnoli.

- 25 anos de paisagismo em São Paulo: 1960-1985, mestranda Maria Assunção R. Franco

- Orient. professora Miranda M. Magnoli.

No aspecto referente à paisagem regional:

- Análise geossistêmica em geografia como subsídio ao planejamento paisagístico, professora Maria A. Faggin Pereira Leite - Orient. professor Carlos A. Figueiredo Monteiro.

- Planejamento da paisagem: estudo da região de Sorocaba, mestrando Paulo R. Mesquita Pellegrino - Orient. professora Miranda M. Magnoli.

- Planejamento em área de proteção ambiental, pesquisadora Helena Napoleón Degreas

- Orient. professora Miranda M. Magnoli.

- Estação ecológica: preservação do vale do Paranapanema, mestrando Joamélio Tanaka - Orient. professor Sylvio Sawaya.

No aspecto referente à paisagem metropolitana:

- Espaços livres e urbanização: uma introdução a aspectos da paisagem metropolitana e a morfologia da urbanização, professora Miranda M. Magnoli.

- Aspectos paisagísticos da cidade de Natal, mestranda Catharina P. C. dos Santos Lima - Orient. professora Miranda M. Magnoli.

- Preservação do meio físico e ecológico em Carapicuíba como área periférica-metropolitana, mestranda Vera C. O. Fonseca - Orient. professor Gian Carlo Gasperini.

Nos aspectos da paisagem urbana, do "lugar" e dos materiais:

- Desenho da paisagem urbana e verticalização; o caso de São Paulo, doutorando professor Silvio S. Macedo - Orient. professora Miranda M. Magnoli.

- Implicações de controle ambiental no âmbito do uso social de um fragmento urbano, doutorando Luiz C. Chichierchio - Orient. professor Sylvio Sawaya.

- Mutação de paisagem urbana: o bairro de Higienópolis e arredores, professor Silvio S. Macedo - Orient. professora Miranda M. Magnoli.

- Critérios e padrões paisagísticos para o desenho do sistema viário urbano: estudo de casos típicos em São Paulo, mestranda Rosa Grena Kliass - Orient. professor Lúcio Grinover.

- O campus universitário da USP como espaço cultural metropolitano, pesquisadora Cássia Regina Mariano - Orient. professora Miranda M. Magnoli.

- A paisagem de um bairro de periferia: São Miguel Paulista, pesquisador Euler Sandeville Jr.

- Orient. professora Miranda M. Magnoli. 
- Mutação da paisagem urbana na avenida São Luiz, bolsista I. C. Paula da Cruz Landim - Orient. professor Silvio S. Macedo.

- Desenho da paisagem habitacional, bolsista I. C. Fábio M. Gonçalves - Orient. professor Silvio S. Macedo.

- Espaços livres junto às habitações: estudo de áreas implantadas, professora Ayako Nishikawa

- Orient. professora Miranda M. Magnoli.

- O significado do espaço público junto aos transportes de massa: as praças das estações de metrô em São Paulo, mestrando professor Vladimir Bartalini - Orient. professora Miranda M. Magnoli.

- Apropriação de praças públicas - espaços no Rio de Janeiro, mestranda Vera Lúcia Cardim - Orient. professora Miranda M. Magnoli.

- Lugares urbanos na evolução metropolitana, pesquisadora Iracy S. Leme - Orient. professora Miranda M. Magnoli.

- A vegetação nos projetos de paisagismo, mestrando Benedito Abbud - Orient. professora Miranda M. Magnoli.

Obs.: Texto publicado originalmente na revista Paisagem e Ambiente - Ensaios I, 1986. Reeditado na Revista Paisagem e Ambiente - Ensaios (Edição Especial I e II), 1994. 